\title{
Piccardi-Lassueur-Graham-Little syndrome associated with frontal fibrosing alopecia*
}

\author{
Andrea Alejandra Catalán Griffiths ${ }^{1}$ \\ Ana Iglesias Plaza ${ }^{1}$
}

\author{
Maribel Iglesias Sancho ${ }^{1}$
}

DOI: http:/ / dx.doi.org/10.1590/abd1806-4841.20176741

\begin{abstract}
Piccardi-Lassueur-Graham-Little syndrome is a rare entity characterized by progressive scarring alopecia of the scalp and keratotic papules on hairless skin, associated with non-scarring alopecia in the axilla and pubic area or lichen planus lesions. We describe the case of a 70-year-old woman who presented a Piccardi-Lasseur-Graham-Little syndrome, along with frontal fibrosing alopecia.
\end{abstract}

Keywords: Alopecia; Lichen planus; Lichen planus, oral

\section{INTRODUCTION}

Piccardi-Lassueur-Graham-Little syndrome (PLGLS) is a rare entity characterized by multifocal cicatricial alopecia of the scalp, keratotic papules on hairless skin, and non-cicatricial alopecia of the axillary and pubic regions. Patients can present at least one episode of cutaneous or mucous lichen planus in the course of the disease. ${ }^{1}$ PLGLS has rarely been described as associated with other types of alopecia. The present study describes a case of PLGLS associated with frontal fibrosing alopecia (FFA).

\section{CASE REPORT}

A 70-year-old woman presented a clinical history of progressive asymptomatic rough skin lesions for the last three years located on the trunk and scalp, along with oral discomfort. Past medical history was unremarkable.

Physical examination revealed keratotic papules located on the arms, abdomen, and back (Figures 1 and 2). Non-cicatricial alopecia was observed in the axillar and pubic regions (Figure 3). She also presented plaques of cicatricial alopecia on the scalp, along with a recession of the frontotemporal hairline and a loss of eyebrows (Figures 4 and 5). Finally, white reticular lesions on the oral mucosa were observed (Figure 6).

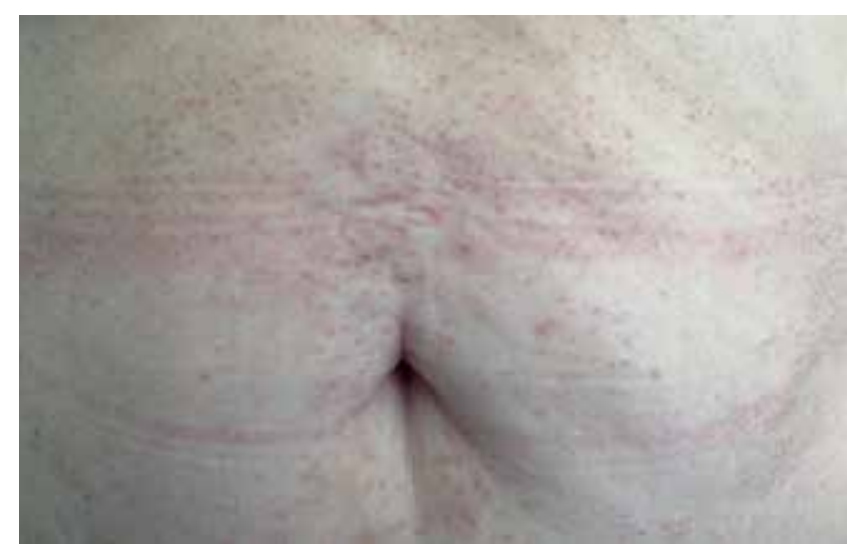

FIGURE 1: Keratotic papules on the abdomen

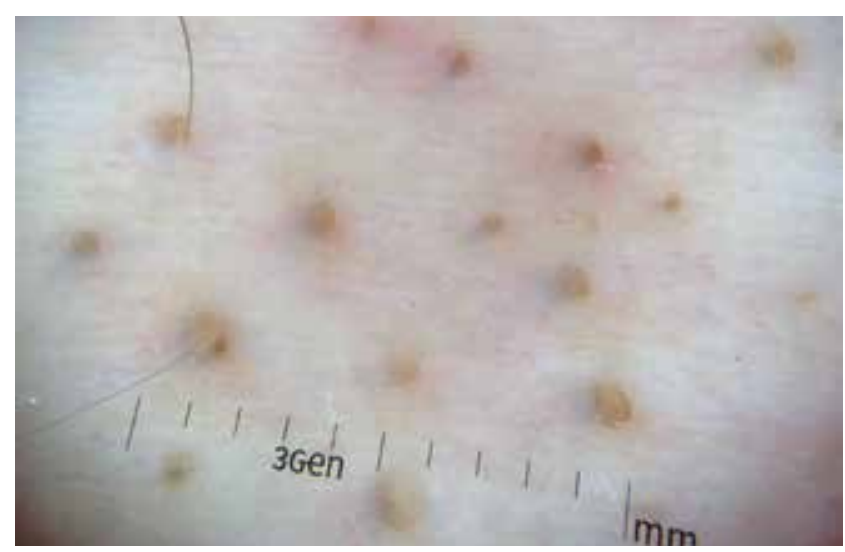

Figure 2: Dermoscopy of follicular hyperkeratotic plugs

Received on 07.12.2016.

Approved by the Advisory Board and accepted for publication on 17.02.2017.

* Work performed at the Sagrat Cor University Hospital - Barcelona, Spain.

Financial support: none.

Conflict of interest: none.

1 Department of Dermatology, Hospital Universitari Sagrat Cor - Barcelona, Spain.

@2017 by Anais Brasileiros de Dermatologia 


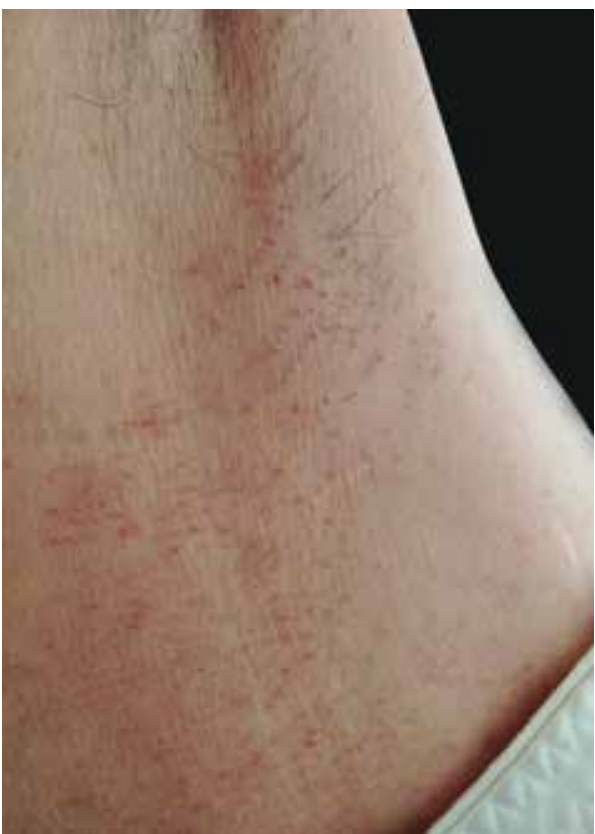

FIGURE 3: Non-cicatricial alopecia on the axillary region

Histophatological examination of a scalp plaque biopsy showed an orthokeratotic epidermis and focal hypergranulosis, in addition to lichenoid infiltrates with dermo-epidermal detachment and dermal fibrosis. A second skin biopsy from the abdominal region showed follicular hyperkeratosis. Complementary examinations, including a complete blood test, thyroid hormone profile, autoimmune tests, and viral serologies, were normal.

With the diagnosis of PLGLS associated with FFA and oral lichen planus, treatment with oral Acitretin $25 \mathrm{mg}$ daily and topical clobetasol propionate foam for the scalp were begun. After 2 months a significant decrease in lesions in the oral mucosa and skin, along with less inflammatory activity on alopecic areas, was observed.

\section{DISCUSSION}

Since its first description in 1931, the etiology of PLGLS has been under debate. Previous studies focusing on clinical, histological, and immunofluorescent features of PLGLS suggest that it could be a variant of lichen planopilaris (LPP), characterized by a lichenoid dermatosis and progressive cicatricial alopecia. ${ }^{2}$

Several associations have been described with this syndrome, including the Hepatitis B virus (HBV) vaccination, HLA DR-1 genetic susceptibility, and androgen insensitivity syndrome. ${ }^{2,3}$

FFA is a primary lymphocytic cicatricial alopecia with a distinctive clinical pattern of progressive frontotemporal hairline recession and eyebrow loss that mainly affects postmenopausal women. ${ }^{4}$ To the best of our knowledge, this syndrome has only been described in one case of FFA with PLGLS components. Moreover, it is controversial whether or not PLGLS represents a form of LPP, since both present similar characteristics of perifollicular inflammation, follicular hyperkeratosis, and cicatricial alopecia, even when this association was not clinically found in the largest multicenter study of FFA described in literature. ${ }^{4-8}$

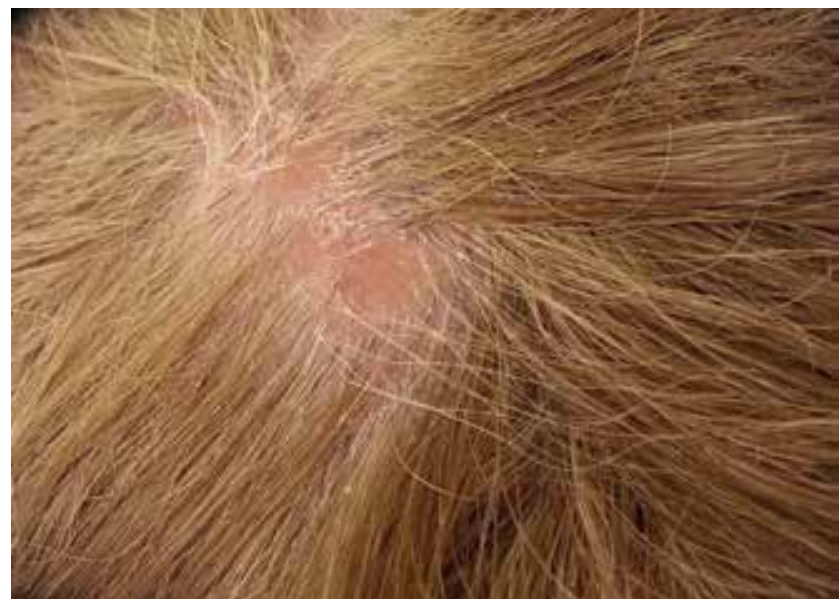

FIGURE 4: Alopecic areas with perifollicular erythema and desquamation on the scalp

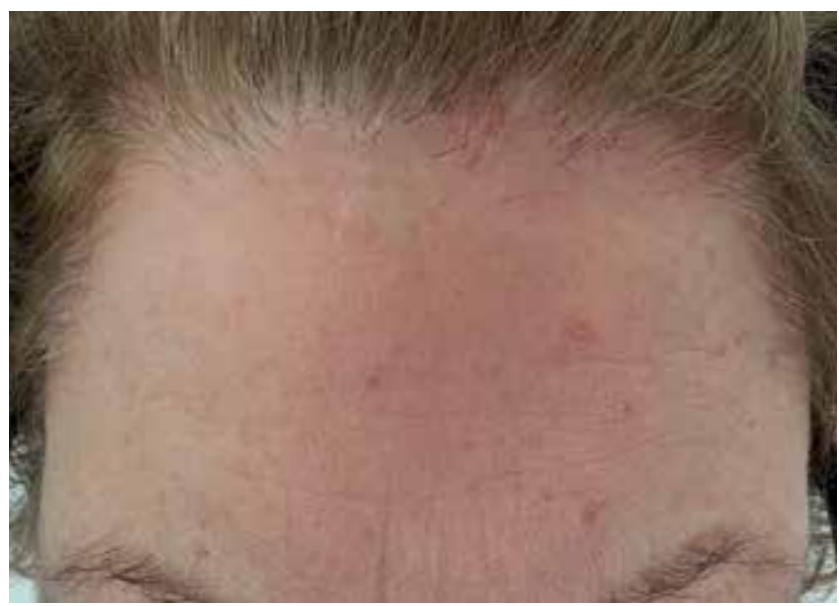

FIGURE 5: Frontal Fibrosing Alopecia (FFA): recession of the frontotemporal hairline and loss of eyebrows

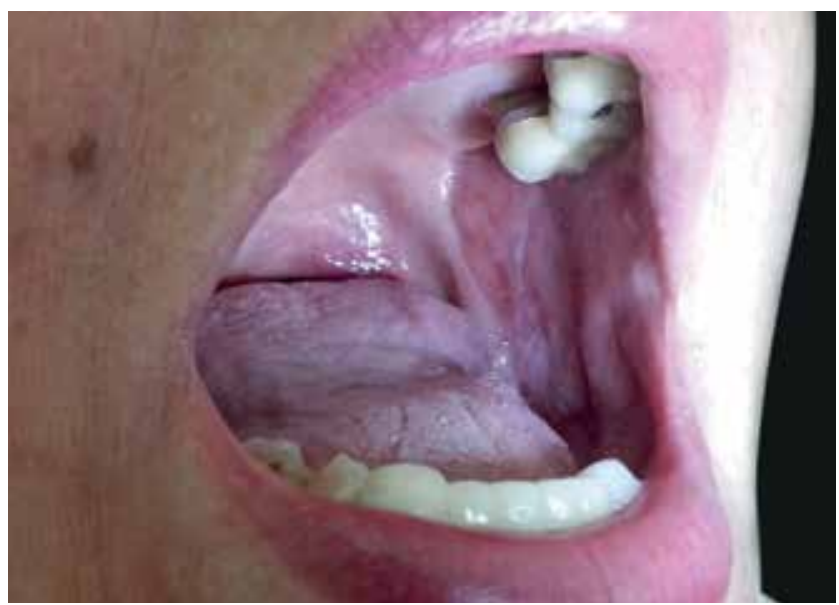

FIGURE 6: White reticular lesions involving the oral mucosa

Although its pathogenic mechanism remains unclear, following the description of the first antibody against the INCENP protein (a major component of the centromere during several phases of the mitotic cell cycle), an autoimmune etiology was more 
recently proposed. This protein is considered to be one of the main antigens in this syndrome. ${ }^{9}$

Therapeutic options include topical or systemic steroids, retinoids, PUVA therapy, Cyclosporine or Thalidomide with variable clinical responses. ${ }^{10}$

\section{REFERENCES}

1. Steglich RB, Tonoli RE, Pinto GM, Müller FM, Guarenti IM, Duvelius ES. GrahamLittle Piccardi Lassueur syndrome: case report. An Bras Dermatol. 2012;87:775-7.

2. Pai VV, Kikkeri NN, Sori T, Dinesh U. Graham-little piccardi lassueur syndrome: an unusual variant of follicular lichen planus. Int J Trichology. 2011;3:28-30.

3. Yorulmaz A, Artuz F, Er 0, Guresci S. A case of Graham-Little-Piccardi-Lasseur syndrome. Dermatol Online J. 2015;21. pii: 13030/qt7gj157xg.

4. Vañó-Galván S, Molina-Ruiz AM, Serrano-Falcón C, Arias-Santiago S, RodriguesBarata AR, Garnacho-Saucedo G, et al. Frontal fibrosing alopecia: a multicenter review of 355 patients. J Am Acad Dermatol. 2014;70:670-8.

5. Abbas 0 , Chedraoui A, Ghosn S. Frontal fibrosing alopecia presenting with components of Piccardi-Lassueur-GrahamLittle syndrome. J Am Acad Dermatol. 2007;57:S15-8.

6. Fernandez-Flores A, Manjón JA. Histopathology of keratotic papules of the limbs in frontal fibrosing alopecia. J Cutan Pathol. 2016;43:468-71.
In conclusion, we have presented an uncommon association of PLGLS and FFA. PLGLS should be suspected in patients with progressive cicatricial scalp alopecia, follicular hyperkeratotic lesions on the trunk and extremities, and alopecia of the pubic and axillary regions. The classification of both PLGLS and FFA remains unclear, and both could represent a form of LPP. $\square$
7. Chew AL, Bashir SJ, Wain EM, Fenton DA, Stefanato CM. Expanding the spectrum of frontal fibrosing alopecia: a unifying concept. J Am Acad Dermatol. 2010;63:653-60.

8. Meinhard J, Stroux A, Lünnemann L, Vogt A, Blume-Peytavi U. Lichen planopilaris: Epidemiology and prevalence of subtypes - a retrospective analysis in 104 patients. J Dtsch Dermatol Ges. 2014;12:229-35, 229-36.

9. Rodríguez-Bayona B, Ruchaud S, Rodríguez C, Linares M, Astola A, Ortiz M, et al. Autoantibodies against the chromosomal passenger protein INCENP found in a patient with Graham Little-Piccardi-Lassueur syndrome. J Autoimmune Dis. 2007;4:1.

10. Zegarska B, Kallas D, Schwartz RA, Czajkowski R, Uchanska G, Placek W. GrahamLittle syndrome. Acta Dermatovenerol Alp Pannonica Adriat. 2010;19:39-42.

\author{
MAILING ADDRESS: \\ Andrea Alejandra Catalán Griffiths \\ Carrer de Viladomat, 288 \\ 08029. Barcelona \\ Spain \\ E-mail:a.catalan.gr@gmail.com
}

How to cite this article: Catalán Griffiths A, Iglesias Sancho M, Iglesias Plaza A. Piccardi-Lassueur-Graham-Little syndrome associated with frontal fibrosing alopecia. An Bras Dermatol. 2017;92(6): 867-9. 